\begin{tabular}{|l|l|}
\hline Postprint Version & Final draft post-refereeing \\
\hline Journal website & http://sciencedirect.com/science/journal/01650327 \\
\hline Pubmed link & $\underline{\text { http://www.ncbi.nlm.nih.gov/pubmed/17509695 }}$ \\
\hline DOI & $\underline{10.1016 / j . j a d .2007 .04 .011}$ \\
\hline
\end{tabular}

\title{
Healthcare and preventive services utilization of elderly Europeans with depressive symptoms
}

\author{
${ }^{1,3}$ Peytremann-Bridevaux I, ${ }^{2}$ Voellinger R, ${ }^{1}$ Santos-Eggimann B. \\ ${ }^{1}$ Health Services Research Unit, Institute of Social and Preventive Medicine, University of \\ Lausanne \\ ${ }^{2}$ Health Care Evaluation Unit, Institute of Social and Preventive Medicine, University of \\ Lausanne. \\ ${ }^{3}$ Institute of Health Economics and Management, University of Lausanne.
}

\section{Corresponding author:}

I. Peytremann-Bridevaux, MD, MPH, DSc

Institute of Social and Preventive Medicine

17 Bugnon

$\mathrm{CH}-1005$ Lausanne, Switzerland

Tel: \#41 213147284

Fax: \#41 213147373

Email: Isabelle.Peytremann-Bridevaux@chuv.ch

\begin{abstract}
Background: Depressive symptoms are associated with increased healthcare utilization. However, it is unclear whether depressed individuals experience more or less frequent access to preventive services. Our goal was to investigate the association between depressive symptoms and both utilization of healthcare and preventive services.

Methods: Baseline self-reported data (2004) from non-institutionalized individuals aged $\geq 50$ years participating in the Survey of Health, Ageing, and Retirement in Europe (SHARE) were used. Of 18'560 respondents to the baseline questionnaire, 13'580 answered the supplementary questionnaire, which included measures of preventive services. Healthcare utilization during the previous 12 months, including outpatient visits, medication, hospitalization, surgery, and home healthcare were assessed. Preventive service measures assessed the participation in influenza immunization and colorectal and breast cancer screening. Depression status was assessed with the EURO-D, a validated instrument for which a score $>3$ defines clinically significant depressive symptoms. Logistic regressions were performed adjusting for age, gender, socioeconomic status, behavioral risk, chronic disease, disability, and country of residence.

Results: The estimated prevalence of depressive symptoms was $28.2 \%$. Depressive symptoms were associated with significantly greater use of all healthcare domains but not preventive services, with the exception of colorectal cancer screening. Similar trends were found for each country of residence and for both genders.

Limitations: It was not known whether medical tests were used for screening or diagnostic purposes.
\end{abstract}


Conclusions: SHARE data suggest that patients with depressive symptoms are frequent users of healthcare but not preventive services. Low screening rates may reflect missed screening opportunities rather than a lack of screening opportunities.

Key words: healthcare utilization; preventive services; depressive symptoms; populationbased survey.

\section{Introduction}

Depressive symptoms are a major public health problem because of their high prevalence, their detrimental effect on health (Braam et al., 2005) and their association with relatively frequent use of medical services (Bijl and Ravelli, 2000; Huang et al., 2000). In the elderly, the average prevalence of clinically relevant depressive syndromes (major and minor depression) is $13.5 \%$ (Beekman et al., 1999).

Little research has been published regarding the receipt of preventive services by individuals presenting depressive symptoms, and the results of such research are discordant (Horvitz-Lennon et al., 2006, Lasser et al., 2003, Mangtani et al., 2005, Pirraglia et al., 2004; Werneke et al., 2006). The first aim of the present study was to assess the association between depressive symptoms and the use of health services. The second was to examine whether individuals with and without depressive symptoms received similar levels of preventive services.

\section{Methods}

\subsection{Data Sources and Participants}

The Survey of Health, Ageing, and Retirement in Europe (SHARE) [Börsch-Supan et al., 2005a) included 10 countries in 2004 (Austria, Denmark, France, Germany, Greece, Italy, the Netherlands, Spain, Sweden, and Switzerland). Baseline data were collected from noninstitutionalized individuals aged $\geq 50$ years using standardized face-to-face questionnairebased interviews (survey questionnaires available online: http://www.share-project.org/). Respondents to the baseline questionnaire (overall response rate: $61.8 \%$ [Börsch-Supan et al., 2005b]) were given a self-administered supplementary questionnaire that they had to return by mail.

Of the 19 '123 eligible respondents, $563(2.9 \%)$ were excluded due to the absence of information regarding depressive symptoms $\left(n=18^{\prime} 560\right)$, and $15^{\prime} 380$ out of the latter $(83 \%)$ responded to the supplementary questionnaire. These respondents were slightly more likely to be married, better educated, wealthier and more physically active. They also reported better subjective health and were less likely to present depressive symptoms.

The study's two samples consisted of the 18'560 individuals who answered the baseline questionnaire and the 15'380 individuals who answered both the baseline and supplementary questionnaire.

\subsection{Measures}

Except for preventive services information which was collected using the supplementary questionnaire, data were extracted from the baseline questionnaire. All measures were self-reported.

The primary independent variable was the presence or absence of clinically significant depressive symptoms. This was defined by a score $>3$ on the EURO-D scale, a validated instrument developed in Europe [Prince et al., 1999], scale includes 12 items (total score ranges between 0 and 12; higher scores indicate increased severity of depressive symptoms). 
The main outcomes were measures of healthcare utilization during the previous 12 months: use of medical care (in-outpatient, yes/no), number of ambulatory care visits, number of visits to general practitioners (among respondents with at least one ambulatory care visit), consultation of specialists (yes/no), hospital admission (yes/no), in-outpatient surgery (yes/no), number of medication taken $\geq 1 \mathrm{x} /$ week, use of home healthcare (yes/no), use of domestic help (yes/no), influenza vaccination (last year; individuals $\geq 65$ years), participation in colorectal cancer (endoscopic screening; last 10 years; individuals $\geq 50$ years; no history of colorectal cancer), and breast cancer screening (mammogram; past 2 years; women $\geq 50$ years; no history of breast cancer). All outcomes were defined as binary variables. Data for the number of total and general practitioner ambulatory care visits and the number of medication taken were dichotomized into categories of high (> sample median) and low ( $\leq$ sample median) use.

Potential confounders considered were: age, gender, marital status, years of education, household income adjusted for the size of the household, smoking, alcohol consumption, chronic diseases, disability and country of residence.

\subsection{Statistical analysis}

First we compared characteristics and healthcare use between groups using the chisquared test and ANOVA, for categorical and continuous variables, respectively. Then, to assess the odds of a given outcome in individuals with versus without depressive symptoms, multiple logistic regression models were constructed. The joint Wald test was used to evaluate interactions (depressive symptoms*country of residence, depressive symptoms*gender). Analyses were first performed on pooled data, and then for each country of residence, using Stata 8.0. None of the variables considered had missing data $\geq 2 \%$.

\section{Results}

Twenty-eight percent of European men and women presented clinically significant depressive symptoms. The estimated prevalence ranged from $18.0 \%$ in Denmark to $37.6 \%$ in Spain (Table 1). Table 2 summarizes the characteristics of the study population. In the group with depressive symptoms, there was a greater proportion of women, individuals were less educated, reported more chronic diseases and worse subjective health.

The crude health services utilization analyses (Table 3 ) show that a higher percentage of individuals with versus without depressive symptoms used healthcare, with the exception of breast cancer screening. The odds ratios (ORs) and 95\% confidence interval (Cl) for healthcare utilization and preventive services are presented in Table 4. Individuals with depressive symptoms were significantly more likely to be users of healthcare, and these relations were not explained by comorbidities. Indeed, the adjusted ORs for healthcare utilization ranged between $1.4(95 \% \mathrm{Cl} 1.2-1.7)$ for any surgery to $2.2(95 \% \mathrm{Cl} 1.9-2.6)$ for the use of $\geq 2$ drug categories. While the presence of depressive symptoms was not associated with decreased or increased receipt of influenza immunization or breast cancer screening, the OR for colorectal cancer screening was significant. Adjustment for the number of outpatient visits or for rural residence did not change the point estimate or its significance.

Country-level analyses showed similar trends for use of healthcare and preventive services. In addition, the associations between depressive symptoms and use of healthcare and preventive services did not statistically vary by country or gender $(P$-value $>0.05$ for interactions of depressive symptoms*country and depressive symptoms ${ }^{*}$ gender).

Additional analysis of healthcare utilization for the subgroup of respondents to the supplementary questionnaire yielded ORs similar to those reported in Table 4. 


\section{Discussion}

Our results show that depressive symptoms were independently and significantly associated with greater use of healthcare services. However, this increased number of contacts with the healthcare system (opportunities) did not affect the receipt of influenza immunization or breast cancer screening.

Strengths of our study include a large database from 10 European countries and the use of standardized questionnaires and procedures. However, it has some limitations. For example, it was not known whether tests were performed for screening or diagnostic purposes. This could have affected our results, although in an unknown manner. In addition, the time windows for colorectal cancer screening were partly longer than those usually recommended (a 10-year limit was used in this study instead of recommended sigmoidoscopy every 5 years and colonoscopy every 10 years). This may have resulted in a non-differential misclassification across categories of depressive symptoms. Also, the crosssectional nature of the data precludes any definitive conclusions regarding causal relationships, and the use of self-reported data may have resulted in reporting and/or recall biases.

Concordant with previous population-based studies from several countries (Beekman et al., 1997; Fischer et al., 2002; Himelhoch et al., 2004 McCracken et al., 2006; Rowan et al., 2002), our results reveal an association between depressive symptoms and general healthcare use, which was not fully explained by chronic diseases and/or disability. Together with the fact that most depressed individuals who visit their physician focus distress on somatic symptoms, these results suggest that depression may be independently associated with healthcare utilization.

The findings of an association between depressive symptoms and preventive services are not consistent with previously published studies (Mangtani et al., 2005; Pirraglia et al., 2004; Werneke et al., 2006), and do not confirm the negative impact of depressive symptoms on receipt of preventive services (breast cancer screening and influenza immunization). There are several possible explanations for this difference. First, it may be difficult to access severely depressed individuals with population-based surveys. The slightly lower response rate (RR) to the supplementary questionnaire for participants with worse EURO-D scores supports the idea of a negative association between depression and survey participation. Also, the EURO-D cut-off $>3$ might have been too low to detect differences in receipt of preventive services between individuals with and without depressive symptoms. However, additional analyses using more categories of depressive symptoms did not support this hypothesis. Second, the more favorable health-related behaviors and profiles of the respondents versus non-respondents of the supplementary questionnaire could have attenuated differences between individuals with and without depressive symptoms, because they may have been too similar with regard to demographic and health characteristics. Third, the existence of competing demands might compel physicians to focus on depression management at the expense of health prevention, such that higher overall healthcare utilization occurs without increased use of preventive services.

We are not aware of other studies evaluating the association between depression and colorectal screening, and suggest the following explanations for our finding of greater use of colorectal screening in depressed people. In the context of overall low use of a screening test, a long screening window could induce more colorectal cancer screening for individuals suffering from depressive symptoms, since they use more healthcare services. However, adjustment for the number of ambulatory care visits invalidates this explanation. The increased report of colorectal cancer screening might also be a consequence of the more frequent report of gastrointestinal symptoms (Garakani et al., 2003), and subsequent diagnostic endoscopies, for individuals with depressive symptoms. In contrast to breast cancer, which often presents without signs or symptoms, unspecific digestive complaints that precede colorectal cancer may prompt the performance of gastrointestinal endoscopies. As 
physicians tend to focus more on health complaints than health promotion or prevention, this could explain some of the difference in receipt of preventive services concerning colorectal cancer versus breast cancer and influenza.

In conclusion, this study sheds light on the association between depressive symptoms and healthcare utilization and preventive services. As expected from the greater disease burden of individuals suffering from depressive symptoms, there was increased use of all dimensions of care. With the exception of colorectal cancer screening, this was not accompanied by an increase in receipt of preventive services. Healthcare professionals should be aware that low screening rates among individuals with depressive symptoms may be due to missed screening opportunities rather than a lack of screening opportunities.

\section{Acknowledgments}

"This paper uses data from the early release 1 of SHARE 2004. This release is preliminary and may contain errors that will be corrected in later releases. The SHARE data collection has been primarily funded by the European Commission through the 5th framework programme (project QLK6-CT-2001-00360 in the thematic programme Quality of Life). Additional funding came from the US National Institute on Aging (U01 AG09740-13S2, P01 AG005842, P01 AG08291, P30 AG12815, Y1-AG-4553-01 and OGHA 04-064). Data collection in Austria (through the Austrian Science Fund, FWF), Belgium (through the Belgian Science Policy Office) and Switzerland (through BBW/OFES/UFES) was nationally funded. The SHARE data set is introduced in Börsch-Supan et al. (2005); methodological details are contained in Börsch-Supan and Jürges (2005)."

\section{Conflict of interest}

None of the three authors have conflict of interest, of any form, to declare.

\section{References}

Beekman, A.T., Deeg, D.J., Braam, A.W., Smit, J.H., Van Tilburg, W.. 1997. Consequences of major and minor depression in later life: a study of disability, well-being and service utilization. Psychol Med. 27, 1397-1409.

Beekman, A.T., Copeland, J.R., Prince, M.J., 1999. Review of community prevalence of depression in later life. Br J Psychiatry. 174, 307-311

Berkman, L.F., Berkman, C.S., Kasl, S., Freeman, D.H. Jr, Leo, L., Ostfeld, A.M., CornoniHuntley, J., Brody, J.A., 1986. Depressive symptoms in relation to physical health and functioning in the elderly. Am J Epidemiol. 124, 372-388.

Bijl, R.V., Ravelli, An, 2000. Psychiatric morbidity, service use, and need for care in the general population: results of The Netherlands Mental Health Survey and Incidence Study. Am J Public Health. 90, 602-607.

Börsch-Supan, A., Hank, K., Jürges, H., 2005a. A new comprehensive and international view on ageing: introducing the "Survey of Health, Ageing and Retirement in Europe". Eur $\mathrm{J}$ Ageing. 2, 245-253.

Börsch-Supan, A., Jürges, H., (Eds), 2005b. The survey of health, ageing and retirement in Europe: Methodology. Mannheim Research Institute for the Economics of Aging (MEA), Mannheim.

Braam, A.W., Prince, M.J., Beekman, A.T., Delespaul, P., Dewey, M.E., Geerlings, S.W., Kivela, S.L., Lawlor, B.A., Magnusson, H., Meller, I., Peres, K., Reischies, F.M., Roelands, M., Schoevers, R.A., Saz, P., Skoog, I., Turrina, C., Versporten, A., Copelan, 
J.R., 2005. Physical health and depressive symptoms in older Europeans. Results from EURODEP. Br J Psychiatry. 187, 35-42.

Fischer, L.R., Wei, F., Rolnick, S.J., Jackson, J.M., Rush, W.A., Garrard, J.M., Nitz, N.M., Luepke, L.J., 2002. Geriatric depression, antidepressant treatment, and healthcare utilization in a health maintenance organization. J Am Geriatr Soc. 50, 307-312.

Garakani, A., Win, T., Virk, S., Gupta, S., Kaplan, D., Masand, P.S., 2003. Comorbidity of irritable bowel syndrome in psychiatric patients: a review. Am J Ther. 10, 61-67.

Himelhoch, S., Weller, W.E., Wu, A.W., Anderson, G.F., Cooper, L.A., 2004. Chronic medical illness, depression, and use of acute medical services among Medicare beneficiaries. Med Care. 42, 512-521.

Horvitz-Lennon, M., Kilbourne, A.M., Pincus, H.A., 2006. From silos to bridges: meeting the general health care needs of adults with severe mental illnesses. Health Aff (Millwood) 25, 659-369.

Huang, B.Y., Cornoni-Huntley, J., Hays, J.C., Huntley, R.R., Galanos, A.N., Blazer, D.G., 2000. Impact of depressive symptoms on hospitalization risk in community-dwelling older persons. J Am Geriatr Soc. 48, 1279-1284.

Lasser, K.E., Zeytinoglu, H., Miller, E., Becker, A.E., Hermann, R.C., Bor, D.H., 2003. Do women who screen positive for mental disorders in primary care have lower mammography rates? Gen Hosp Psychiatry. 25, 214-216.

Mangtani, P., Breeze, E., Kovats, S., Ng, E.S., Roberts, J.A., Fletcher, A., 2005. Inequalities in influenza vaccine uptake among people aged over 74 years in Britain. Prev Med. 41, 545-553.

McCracken, C., Dalgard, O.S., Ayuso-Mateos, J.L., Casey, P., Wilkinson, G., Lehtinen, V., Dowrick, C., 2006. Health service use by adults with depression: community survey in five European countries. Evidence from the ODIN study. Br J Psychiatry. 189, 161-167.

Pirraglia, P.A., Sanyal, P., Singer, D.E., Ferris, T.G., 2004. Depressive symptom burden as a barrier to screening for breast and cervical cancers. J Womens Health (Larchmt). 13, 731-738.

Prince, M.J., Reischies, F., Beekman, A.T., Fuhrer, R., Jonker, C., Kivela, S.L., Lawlor, B.A., Lobo, A., Magnusson, H., Fichter, M., van Oyen, H., Roelands, M., Skoog, I., Turrina, C., Copeland, J.R., 1999. Development of the EURO-D scale--a European, Union initiative to compare symptoms of depression in 14 European centres. Br J Psychiatry. 174, 330338.

Rowan, P.J., Davidson, K., Campbell, J.A., Dobrez, D.G., MacLean, D.R., 2002. Depressive symptoms predict medical care utilization in a population-based sample. Psychol Med. 32, 903-908.

Werneke, U., Horn, O., Maryon-Davis, A., Wessely, S., Donnan, S., McPherson, K., 2006. Uptake of screening for breast cancer in patients with mental health problems. J Epidemiol Community Health. 60, 600-605. 
Table 1

Estimated prevalence of depressive symptoms, by country (respondents to baseline questionnaire, $n=18^{\prime} 560$ )

\begin{tabular}{lll}
\hline & Sample size & $\begin{array}{l}\text { Presence of depressive } \\
\text { symptoms }\end{array}$ \\
\cline { 2 - 3 } & & $\%$ \\
\cline { 2 - 3 } & & \\
Austria & 1893 & 19.7 \\
Denmark & 1557 & 18.0 \\
France & 1590 & 33.4 \\
Germany & 2243 & 21.2 \\
Greece & 1894 & 24.9 \\
Italy & 1962 & 33.6 \\
The Netherlands & 2213 & 21.2 \\
Spain & 1735 & 37.6 \\
Sweden & 2538 & 20.5 \\
Switzerland & 936 & 18.9 \\
\cline { 2 - 2 } & & \\
All 10 countries & 18560 & 28.2 \\
\hline
\end{tabular}


Table 2

Characteristics of the participants, according to the presence/absence of depressive symptoms (respondents to the baseline questionnaire, $n=18$ '560)

\begin{tabular}{|c|c|c|}
\hline & $\begin{array}{l}\text { Absence of depressive } \\
\text { symptoms } \\
\left(n=14^{\prime} 058\right)\end{array}$ & $\begin{array}{l}\text { Presence of depressive } \\
\text { symptoms } \\
\left(n=4{ }^{\prime} 502\right)\end{array}$ \\
\hline $\begin{array}{l}\text { Age, mean }(\mathrm{SD}) \\
\text { Aged } \geq 65 \text { years }\end{array}$ & $\begin{array}{l}64.4(0.2) \\
46.0 \%\end{array}$ & $\begin{array}{l}67.6(0.3) \\
56.4 \%\end{array}$ \\
\hline Women & $48.3 \%$ & $70.5 \%$ \\
\hline Years of education, mean (SD) & $10.4 \quad(0.07)$ & $8.0 \quad(0.1)$ \\
\hline Married or registered partnership & $70.5 \%$ & $55.9 \%$ \\
\hline Employed & $30.3 \%$ & $16.4 \%$ \\
\hline Currently smoking & $19.2 \%$ & $16.4 \%$ \\
\hline $\begin{array}{l}\text { Neither moderate nor vigorous } \\
\text { physical activity }\end{array}$ & $8.0 \%$ & $23.0 \%$ \\
\hline $\begin{array}{l}\text { Drinking }>2 \text { glasses of alcohol } 5 / 6 \\
\text { days a week }\end{array}$ & $17.4 \%$ & $13.3 \%$ \\
\hline $\begin{array}{l}\text { Number of chronic diseases } \\
\quad 0 \\
1 \\
2 \text { or more }\end{array}$ & $\begin{array}{l}30.9 \% \\
33.5 \% \\
35.6 \%\end{array}$ & $\begin{array}{l}11.5 \% \\
28.8 \% \\
59.7 \%\end{array}$ \\
\hline $\begin{array}{l}\text { Number of health complaints } \\
0 \\
1 \\
2 \text { or more }\end{array}$ & $\begin{array}{l}36.6 \% \\
35.1 \% \\
28.3 \%\end{array}$ & $\begin{array}{l}10.4 \% \\
23.0 \% \\
66.6 \%\end{array}$ \\
\hline $\begin{array}{l}\text { Fair or poor subjective health } \\
\text { (versus excellent, very good, good) }\end{array}$ & $25.8 \%$ & $60.9 \%$ \\
\hline $\begin{array}{l}\text { Difficulties in any of } 5 \text { activities of daily } \\
\text { living }\end{array}$ & $5.6 \%$ & $22.2 \%$ \\
\hline
\end{tabular}


Table 3

Description of health services utilization, according to the presence/absence of depressive symptoms

\begin{tabular}{|c|c|c|c|}
\hline & $\begin{array}{l}\text { Absence of depressive } \\
\text { symptoms }\end{array}$ & $\begin{array}{l}\text { Presence of depressive } \\
\text { symptoms }\end{array}$ & $P$-value \\
\hline \multicolumn{4}{|l|}{ All participants (respondents to the baseline questionnaire } \\
\hline \multicolumn{4}{|l|}{$\left(n=18^{\prime} 560\right):$} \\
\hline No utilization (neither out- nor in-patient) & $13.8 \%$ & $6.2 \%$ & $<0.001$ \\
\hline$\geq 4$ outpatient visits & $52.0 \%$ & $75.3 \%$ & $<0.001$ \\
\hline$\geq 4$ GP visits & $46.0 \%$ & $67.5 \%$ & $<0.001$ \\
\hline Äny visit to specialists & $93.1 \%$ & $94.8 \%$ & 0.07 \\
\hline$\geq 2$ drug categories & $32.4 \%$ & $60.5 \%$ & $<0.001$ \\
\hline Āny hospitalization & $11.3 \%$ & $21.1 \%$ & $<0.001$ \\
\hline Any surgery & $10.5 \%$ & $15.7 \%$ & $<0.001$ \\
\hline Any home healthcare* & $2.5 \%$ & $8.7 \%$ & $<0.001$ \\
\hline Any domestic help* & $2.2 \%$ & $8.5 \%$ & $<0.001$ \\
\hline \multicolumn{4}{|l|}{ Only for respondents to the supplementary questionnaire } \\
\hline \multicolumn{4}{|l|}{$\left(n=15^{\prime} 380\right):$} \\
\hline $\begin{array}{l}\text { Influenza immunization during past year (men and women, } \geq \\
65 \text { years) }\end{array}$ & $52.8 \%$ & $56.0 \%$ & 0.12 \\
\hline $\begin{array}{l}\text { Colorectal cancer screening during past } 10 \text { years: colono or } \\
\text { sigmoido (men and women, no history of colorectal cancer) }\end{array}$ & $16.8 \%$ & $19.2 \%$ & 0.93 \\
\hline $\begin{array}{l}\text { Breast cancer screening during past } 2 \text { years (women, no } \\
\text { history of breast cancer) }\end{array}$ & $53.0 \%$ & $48.0 \%$ & 0.007 \\
\hline
\end{tabular}

*: Because home healthcare and domestic help questions were not asked to Greek and Swiss participants, those two countries were excluded from the analyses of these two outcomes. 
Table 4

Health services utilization odds ratios (OR) and 95\% confidence intervals $(\mathrm{Cl})$, reference category $=$ absence of depressive symptoms

\begin{tabular}{llll} 
Crude & & \multicolumn{2}{c}{ Adjusted $^{*}$} \\
OR & $95 \%$ & OR & $95 \%$ \\
& $\mathrm{Cl}$ & & $\mathrm{Cl}$
\end{tabular}

\section{All participants (respondents to the baseline}

\section{questionnaire $(n=18,560)$ :}

No utilization (neither out- nor in-patient)

$\begin{array}{llll}\mathbf{0 . 4} & 0.3-0.5 & \mathbf{0 . 6} & 0.5-0.7 \\ \mathbf{2 . 8} & 2.5-3.2 & \mathbf{1 . 9} & 1.7-2.2 \\ \mathbf{2 . 4} & 2.2-2.7 & \mathbf{1 . 6} & 1.4-1.8 \\ 1.4 & 0.9-1.9 & \mathbf{1 . 5} & 1.1-2.0 \\ \mathbf{3 . 4} & 3.0-3.7 & \mathbf{2 . 2} & 1.9-2.6 \\ \mathbf{2 . 1} & 1.8-2.4 & \mathbf{1 . 6} & 1.4-1.9 \\ \mathbf{1 . 6} & 1.4-1.8 & \mathbf{1 . 4} & 1.2-1.7 \\ & & & \\ \mathbf{3 . 7} & 2.9-4.7 & \mathbf{1 . 9} & 1.4-2.5 \\ \mathbf{4 . 1} & 3.3-5.2 & \mathbf{1 . 8} & 1.4-2.5\end{array}$

$\geq 4$ outpatient visits

$\geq 4 \mathrm{GP}$ visits

Any visits to specialists

$\mathrm{Cl}$

$\geq 2$ drug categories

Any hospitalization

Any surgery

Any home healthcare*

Any domestic help**

\section{Only for respondents to the supplementary questionnaire}

\section{$(n=15,380)$ :}

Influenza immunization (men and women, $>65$ years)

$1.2 \quad 1.0-1.4 \quad 1.0 \quad 0.8-1.2$

Colorectal cancer screening: colono or sigmoido (men and

$1.2 \quad 1.0-1.4 \quad 1.3 \quad 1.1-1.6$

women, no history of colorectal cancer)

Breast cancer screening (women, no history of breast cancer)

$0.8 \quad 0.7-0.9 \quad 1.0$

$0.8-1.2$

\footnotetext{
* : Adjusting as for age, gender, marital status, ppp-household income, education, smoking, alcohol consumption, presence of

chronic diseases $(\geq 2)$, presence of difficulties in activities of daily living, and country.

**: Because home healthcare and domestic help questions were not asked to Greek and Swiss participants, those two countries were excluded from the analyses of these two outcomes.
} 